\title{
Lutein and $\beta$-Carotene in Selected Asian Leafy Vegetables
}

\author{
Maria V. Chandra-Hioe ${ }^{1^{*}}$, Hassan H. Rahman ${ }^{2}$ and Jayashree Arcot ${ }^{1,2}$ \\ ${ }^{1}$ ARC Training Centre for Advanced Technologies in Food Manufacture, School of Chemical Engineering, UNSW Sydney, NSW 2052, Australia \\ ${ }^{2}$ Food Science and Technology Group, School of Chemical Engineering, UNSW Sydney, NSW 2052, Australia
}

\section{Correspondence to:}

Maria V. Chandra-Hioe

Chemical Sciences Building (F10)

High Street (enter via gate 2)

Sydney NSW 2052, Australia

Tel: +612-93854400

E-mail: m.v.chandra-hioe@unsw.edu.au

Received: April 27, 2017

Accepted: July 25, 2017

Published: July 28, 2017

Citation: Chandra-Hioe MV, Rahman $\mathrm{HH}$, Arcot J. 2017. Lutein and $\beta$-Carotene in Selected Asian Leafy Vegetables. J Food Chem Nanotechol 3(3): 93-97.

Copyright: (C) 2017 Chandra-Hioe et al. This is an Open Access article distributed under the terms of the Creative Commons Attribution 4.0 International License (CC-BY) (http:// creativecommons.org/licenses/by/4.0/) which permits commercial use, including reproduction, adaptation, and distribution of the article provided the original author and source are credited.

Published by United Scientific Group

\begin{abstract}
Carotenoids, such as lutein and $\beta$-carotene are generally recognized as antioxidants. However, only $\beta$-carotene has the pro-vitamin $A$ activity. This study determined lutein and $\beta$-carotene in Asian leafy vegetables using reversed-phase high pressure liquid chromatography (HPLC). The selected samples were Chinese mustard (Brassicajuncea var. rugose), water spinach (Ipomoea aquatic), Chinese spinach (Amaranthus tricolor), coriander (Coriandrum sativum), Chinese flowering cabbage (Brassica parachinensis), Chinese broccoli (Brassica oleracea alboglabra) and Chinese white cabbage (Brassica chinensis). Carotenoids were extracted from samples into $5 \%(\mathrm{w} / \mathrm{v})$ calcium carbonate and acetone. The extracts were then concentrated at $4{ }^{\circ} \mathrm{C}$ and filtered prior to HPLC analysis. The recoveries for $\beta$-carotene and lutein were $132 \%$ and $100 \%$, respectively. The coefficient of variation for inter-variability study was $<3.8 \%$ and for intra-variability study $<11 \%$. The range of $\beta$-carotene in the selected vegetables was 1974-6604 $\mu \mathrm{g} / 100 \mathrm{~g}$ (wet weight basis), or 329-1101 $\mu \mathrm{g} / 100 \mathrm{~g}$ retinol equivalent (RE). Measured lutein contents were between 694$5919 \mu \mathrm{g} / 100 \mathrm{~g}$. Chinese broccoli had the highest pro-vitamin A activity $(1101 \mu \mathrm{g}$ $\mathrm{RE}$ per $100 \mathrm{~g}$ ). The $\beta$-carotene data reported here was useful for estimating the pro-vitamin A intake from consuming the Asian leafy vegetables.
\end{abstract}

\section{Keywords}

Lutein, $\beta$-carotene, Lycopene, HPLC, Asian leafy vegetables, Tomato, Australia

\section{Abbreviations}

RE: Retinol Equivalent; HPLC: High Performance Liquid Chromatography; CV: Coefficients of Variation; WWB: Wet Weight Basis

\section{Introduction}

Carotenoids are lipid-soluble pigments occurring naturally in plants. There are over 700 known carotenoids, including xanthophylls and carotenes [1]. While xanthophylls (e.g. lutein and zeaxanthin) contain oxygen in their molecules, carotenes, such as $\alpha$-carotene and lycopene, contain only hydrocarbon without any oxygen. The main carotene found in Chinese vegetables is $\beta$-carotene and a value greater than $1000 \mu \mathrm{g} / 100 \mathrm{~g}$ can be considered as a good source of vitamin A [2]. Human bodies are able to transform dietary carotenoids to biologically active vitamin A, for example retinol. However, not all carotenoids have this provitamin activity. One retinol equivalent (RE) is commonly used to express the biological activity from various carotenoids, where one $\mathrm{RE}$ corresponds to either $6 \mu \mathrm{g}$ dietary $\beta$-carotene or $12 \mu \mathrm{g}$ other dietary pro-vitamin A [3]. Vitamin A is essential for normal growth and development, immune system function and 
vision. Foods rich in carotenoids can be sourced from carrots, pumpkin, dark green leafy vegetables, eggs and fish [4]. In Australia, as the food choices widen, Asian leafy vegetables become mainstream and they conveniently can be purchased from any supermarket. Traditional Asian vegetables, such as bok choy (Brassica rapa subsp. Chinesis) and kangkong (Ipomoea aquatica), are therefore no longer considered exotic [5].

In solutions, carotenoids are sensitive to light, heat, acid and oxygen, thus making them susceptible to oxidation and isomerization. For this reason, extraction of carotenoids from food matrices must be carried out rapidly and efficiently to minimize any degradation loss. High performance liquid chromatography (HPLC) interfaced with a photo diode array detector has been widely used for quantitation of carotenoids in various food matrices [1]. This study employed HPLC to determine the contents of $\beta$-carotene and lutein in selected Asian leafy vegetables, and lycopene in tomato. Initially, the limits of detection and quantitation, intra-variability and inter-variability studies, accuracy, and recovery were assessed to validate the HPLC method used for quantitation.

\section{Materials and Methods}

\section{Chemicals}

Carotenoid standards: $\beta$-carotene (C4582), lycopene (L9879), and lutein (07168) were purchased from SigmaAldrich (Sydney, Australia). All solvents used were of HPLCgrade (Sigma-Aldrich, Sydney, Australia). Purified water (conductance $\leq 0.1 \mu \mathrm{S} / \mathrm{cm}$ ) was sourced from a Milli-Q system (Millipore, Bedford, MA, USA).

\section{Collection and preparation of samples}

For carotenoids determination, Asian leafy vegetables, such as Chinese mustard (Brassica juncea var. rugose), Chinese spinach (Amaranthus tricolor), coriander (Coriandrum sativum), water spinach (Ipomoea aquatica), Chinese flowering cabbage (Brassica parachinensis), Chinese broccoli (Brassica oleracea alboglabra) and Chinese white cabbage (Brassica chinensis) were obtained in July-August 2014. Each individual sample was a composite sample of the same vegetable acquired from 3 different stores across Sydney (Lakemba, Campsie, Belmore and Kingsford). On the day of purchase, the vegetables were washed, dried and cut into small pieces. The vegetables were then homogenized in a kitchen blender (Breville, Sydney, Australia) and stored at $-80{ }^{\circ} \mathrm{C}$ freezer until further analysis. Freeze-dried 'oxhart' tomato (Lycopersicon esculentum) was selected as a control sample, to monitor the reproducibility of the experimental data. Samples were processed under UV-free light to minimise carotenoids degradation.

\section{Carotenoids extraction}

Extraction of lutein, $\beta$-carotene and lycopene was carried out according to Garcia-Plazaola (1999) with minor modifications. Samples (0.25 g, in duplicate) were initially placed in a mortar and ground into fine powder, while liquid nitrogen was decanted to the samples. Afterwards, $1 \mathrm{~mL}$ $5 \%(\mathrm{w} / \mathrm{v})$ calcium carbonate and acetone were added before the liquid nitrogen fully evaporated. An additional $1 \mathrm{~mL}$ of acetone was pipetted to the pestle and mortar to collect the remaining ground vegetables and the mixture was aliquoted into the same tube [6]. Samples were centrifuged at 10,000 $\mathrm{g}$ for 10 mins at $4{ }^{\circ} \mathrm{C}$ (Thermo-Fisher, Sydney, Australia). Afterwards, the supernatants were concentrated to complete dryness at $4{ }^{\circ} \mathrm{C}$ using a Centrivap (Labconco, Kansas City, $\mathrm{MO}, \mathrm{USA})$. Prior to analysis, samples were resuspended in $1 \mathrm{~mL}$ of the mobile phase, vortexed and transferred into $0.2 \mu \mathrm{m}$ eXtreme filter vials (Thomson, Oceanside, CA, USA).

To assess the accuracy of the method, $\beta$-carotene in the certified reference material (BCR-485 mixed vegetable) obtained from the Institute for Reference Materials and Measurements (Geel, Belgium) was determined. Additionally, the accuracy was verified by standard addition curves; for this purpose, increasing concentrations of standard solutions were added to Chinese white cabbage samples at the start of extraction and then analysed. The extraction efficiency was determined by spiking tomato samples (in duplicate) with known concentrations of carotenoids and then the recovery (\%) was calculated. Samples $(n=8)$ were prepared simultaneously on the same day and analysed in the same run to assess the intra-day variability. The inter-day variability study was evaluated by repeated carotenoids extraction and analysis on three different days.

\section{HPLC analysis}

The HPLC system (Shimadzu LC-20AD series, Kyoto, Japan) used in this study was equipped with a photo diode array detector (SPD-M20A). The HPLC method was adopted from García-Plazaola and Becerril [6] with slight modifications. The aqueous mobile phase (solvent $\mathrm{A}$ ) consisted of acetonitrile (84\%), methanol (2\%) and pre-filtered Tris buffer $(0.1 \mathrm{M} \mathrm{pH}$ $8,14 \%)$. The organic mobile phase (solvent B) contained methanol and ethyl acetate (68:32). The gradient started with $100 \%$ of solvent A before it was ramped up to $100 \%$ solvent $\mathrm{B}$ within 12 mins and kept for the next 6 mins. The initial condition (100\% solvent A) was achieved in 1 minute and the column was re-equilibrated for 6 mins. Carotenoids were separated using a $\mathrm{C}_{18}$ column (Waters Nova-Pak, 3.9 × 150 $\mathrm{mm}, 5 \mu \mathrm{m})$ in a $25 \mathrm{mins}$ run. The flow rate and injection volume were $1.2 \mathrm{~mL} / \mathrm{min}$ and $15 \mu \mathrm{L}$, respectively. The chromatogram was monitored at visible wavelengths and the signal intensities detected at $450 \mathrm{~nm}$ were used for quantitation.

\section{Standard calibration solutions}

Stock standard solutions $(100 \mu \mathrm{g} / \mathrm{mL})$ were prepared by dissolving $1 \mathrm{mg}$ of $\beta$-carotene, lycopene and lutein in the mobile phase, sparged with nitrogen gas and stored in the Eppendorf tubes in a $-80{ }^{\circ} \mathrm{C}$ freezer. Working standard solutions were freshly diluted with the mobile phase on the day of use. The concentrations of lutein and $\beta$-carotene used for the calibration curves ranged from 1.0 to $33 \mu \mathrm{g} / \mathrm{mL}$, and for lycopene between 1.0 to $12 \mu \mathrm{g} / \mathrm{mL}$.

\section{Results and Discussion}

The peaks of lutein, lycopene and $\beta$-carotene were identified based on their retention times and the characteristic 
visible absorption spectra [6]. The spectrum of each standard and the peaks are displayed in Figure 1. The parameters assessed for the method validation were limit of detection, limit of quantitation, inter-day and intra-day variability studies, recoveries, and accuracy.

A.
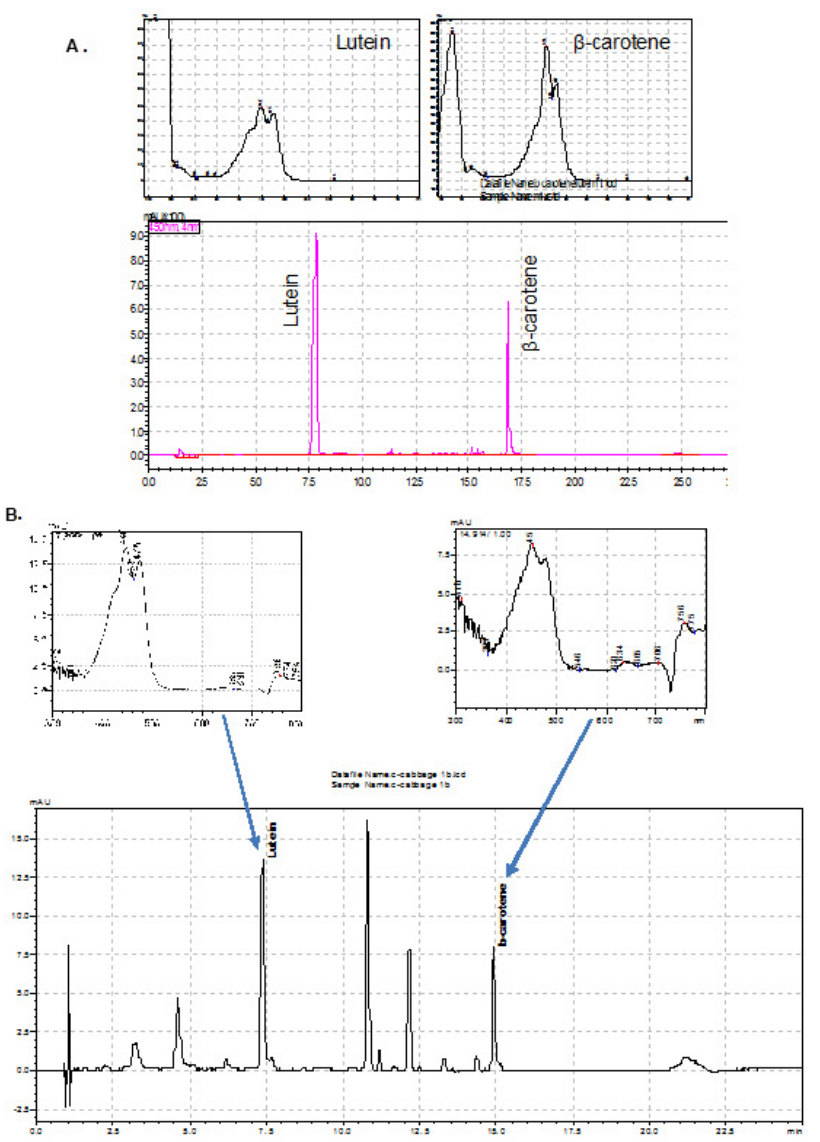

Figure 1: The peaks of lutein and $\beta$-carotene from standards (A) and a vegetable sample (B), and their respective absorption spectra.

The carotenoids standard solution $(0.5 \mu \mathrm{g} / \mathrm{mL})$, detected at a signal to noise ratio $1: 6$, was set as the limit of detection $(200 \mu \mathrm{g} / 100 \mathrm{~g})$. The limit of quantitation was $400 \mu \mathrm{g} / 100 \mathrm{~g}$ (signal to noise ratio 1:11). Standard calibration curves for both analytes were linear over the range 400-13200 $\mu \mathrm{g} / 100 \mathrm{~g}$ $\beta$-carotene $\left(r^{2}=0.994\right)$ and $400-13200 \mu g / 100 \mathrm{~g}$ lutein $\left(r^{2}\right.$ $=0.999)$. The coefficients of variation $(\mathrm{CV})$ for intra-day variability study were $6 \%$ and $11 \%$ for lutein and $\beta$-carotene, respectively. The $\mathrm{CV}$ for $\beta$-carotene presented here was comparable to a previous finding (4.6-10.5\%) for measuring fruits and vegetables samples [7]. In term of inter-variability study, the CV for $\beta$-carotene was $3.8 \%$ and for lutein $3.6 \%$. The recovery was higher for $\beta$-carotene (132\%) than for lutein $(100 \%)$ and lycopene (85\%); the result suggested that lutein and $\beta$-carotene were efficiently released from the plant matrix and there was a minimum degradation loss occurred during sample preparation and analysis. Accuracy of the method was tested by analysis of BCR-485 and plotting the standard addition curves. The analysed $\beta$-carotene value $(21.9 \pm 0.47 \mu \mathrm{g} / \mathrm{g})$ in BCR-485 was within the certified value $(23.7 \pm 1.5 \mu \mathrm{g} / \mathrm{g})$. Lutein and $\beta$-carotene standard addition curves were both linear $\left(r^{2}=0.961\right.$ for $\beta$-carotene and $r^{2}=0.964$ for lutein $)$, thus confirming the accuracy of the method.

\section{Quantitation of Asian leafy vegetables}

Carotenoid values presented in this study were expressed in $\mu \mathrm{g} / 100 \mathrm{~g}$ wet weight basis (WWB). Mean moisture content in the vegetable samples was $96.4 \%$. It has been reported that cooking methods, such as microwaving, 9 mins of boiling, steaming, and stewing does not significantly have an effect on lutein and $\beta$-carotene in green vegetables [8]. Other studies also found that $\beta$-carotene increases after boiling, stewing, steaming and pressure steaming of broccoli [9], in boiled and steamed courgettes/zucchini (Cucurbita pepo L.) and broccoli [10]. While boiling preserved $\beta$-carotene and lutein in leafy greens [11], 1 hour boiling significantly lowers the levels of lutein and $\beta$-carotene [8]. Cooking releases $\beta$-carotene from the plant cell wall and from its protein bound complex $[9,12]$. Based on this premise, lutein and $\beta$-carotene measured in the raw vegetable samples were comparable with their respective cooked samples. The range of $\beta$-carotene in the selected samples was between 1974-6604 $\mu \mathrm{g} / 100 \mathrm{~g}$ or 329-1101 $\mu \mathrm{g}$ RE (Table 1). The $\beta$-carotene contents measured in Chinese spinach $(2524$ $\mu \mathrm{g} / 100 \mathrm{~g})$ and Chinese white cabbage $(2546 \mu \mathrm{g} / 100 \mathrm{~g})$ were comparable with values reported in the previous Australian study, $2000 \mu \mathrm{g} / 100 \mathrm{~g}$ and $2200 \mu \mathrm{g} / 100 \mathrm{~g}$, respectively [13]. Chinese flowering cabbage contained $4142 \mu \mathrm{g} \beta$-carotene per $100 \mathrm{~g}$; this was higher than documented earlier, $2300 \mu \mathrm{g} / 100 \mathrm{~g}$ [13]. The discrepancy in the $\beta$-carotene values was attributed to different extraction protocols used for the studies. In our study, only liquid-liquid extraction was carried out, while in the previous study a combination of liquid-liquid extraction and saponification [13]. Also, other factors, such as analytical errors and the intrinsic difficulty in carotenoids analysis, have to be considered in generating the carotenoids data [14]. The highest $\beta$-carotene, $6604 \mu \mathrm{g} / 100 \mathrm{~g}$, was determined in Chinese broccoli, and the lowest, $1974 \mu \mathrm{g} / 100 \mathrm{~g}$, in Chinese mustard samples (Table 1). Overall, the levels of $\beta$-carotene measured here were higher than earlier findings [2]. A plausible reason for this was due to a degradation loss occurs during a lengthy sample preparation, which leads to low measured carotenoids values [15]. Additional factors affecting the carotenoids contents are cultivar/variety, analysed part of the plants, stage of maturity, climate/geography, harvesting and postharvest handling and processing and storage [14]. Another explanation for the discrepancy in carotenoids contents would be due to season $\mathrm{x}$ variety interactions; flowering cabbage harvested in dry season contained higher $\beta$-carotene $(96000$ $\mu \mathrm{g} / 100 \mathrm{~g}$, dry weight basis) than those harvested in wet season [16]. On the other hand, mean $\beta$-carotene contents in Chinese broccoli collected in wet season is reported to be twice higher than those harvested in dry season [9]. Lower carotenoid contents in the wet season could possibly be due to reduced carotenoid synthesis under high temperatures or increased plant use of carotenoids as photo-protectants under high light intensities [17]. Currently, the carotenoids levels in some Asian leafy vegetables displayed in the Australian Nutrient Table (NUTTAB) are obtained from a 1984's study. Our experimental data provided a valuable update on $\beta$-carotene 
levels from a more recent collection of vegetables.

Table 1: $\beta$-carotene and lutein contents in leafy green vegetables (mean \pm standard deviation) and the retinol equivalent of $\beta$-carotene.

\begin{tabular}{|l|l|l|l|}
\hline & $\begin{array}{l}\boldsymbol{\beta} \text {-carotene } \\
(\boldsymbol{\mu g} / \mathbf{1 0 0} \mathbf{g W W B})\end{array}$ & $\begin{array}{l}\text { Lutein } \\
(\boldsymbol{\mu g} / \mathbf{1 0 0} \mathbf{g W W B})\end{array}$ & $\begin{array}{l}\mathbf{R E} \\
(\boldsymbol{\mu g} / \mathbf{1 0 0} \mathbf{g})\end{array}$ \\
\hline Water spinach & $2446 \pm 225$ & $4144 \pm 211$ & 408 \\
\hline Chinese mustard & $1974 \pm 549$ & $1936 \pm 73$ & 329 \\
\hline Coriander & $2460 \pm 459$ & $5919 \pm 1544$ & 410 \\
\hline Flowering cabbage & $4142 \pm 198$ & $4098 \pm 1200$ & 690 \\
\hline Chinese spinach & $2524 \pm 776$ & $5457 \pm 1206$ & 421 \\
\hline Chinese broccoli & $6604 \pm 963$ & $3917 \pm 180$ & 1101 \\
\hline White cabbage & $2546 \pm 191$ & $694 \pm 203$ & 424 \\
\hline
\end{tabular}

Generally, the lutein content in Asian leafy greens is greater than $\beta$-carotene [16]. The range of lutein in the vegetables samples was between 694 and $5919 \mu \mathrm{g} / 100 \mathrm{~g}$, where lutein was lowest in white cabbage and highest in coriander. Measured lutein in the coriander sample was higher than $\beta$-carotene, which is consistent with a reported value in Taiwanese coriander [11]. According to USDA National Nutrient database, white cabbage contains $48 \mu \mathrm{g}$ lutein and $190 \mu \mathrm{g} \beta$-carotene per $100 \mathrm{~g}$ [18]; both values are much lower than our results. Lutein measured in the Chinese broccoli $(3917 \mu \mathrm{g} / 100 \mathrm{~g})$ was also similar to those sample obtained in the Philippines, $3700 \mu \mathrm{g} / 100 \mathrm{~g}$ [19].

Standard reference materials and certified reference materials are preferably analysed in every batch of analysis [20]. However, this approach is not cost-effective for routine analyses [20]. For this reason, we used freeze-dried 'oxhart' tomato as the in-house reference material, similar to other studies [21, 22]. Measured lycopene in freeze-dried tomato sample was $2271 \mu \mathrm{g} / 100 \mathrm{~g}$ and was lower than $\beta$-carotene $(4123 \mu \mathrm{g} / 100 \mathrm{~g})$. Studies show that lycopene in fresh tomato (per $100 \mathrm{~g}$ ) is higher than $\beta$-carotene; raw tomato contains $3100 \mu \mathrm{g}$ lycopene and $660 \mu \mathrm{g} \beta$-carotene [21]. Graça-Dias et al. also found that tomato has $2300 \mu \mathrm{g}$ lycopene, which is greater than $\beta$-carotene $(390 \mu \mathrm{g} / 100 \mathrm{~g})$. Differences in carotenoids contents of tomatoes are not uncommon in the literature. The carotenoids contents vary considerably even within the same varieties, while other factors including maturity, soil and light intensity play also important roles [22]. Additionally, there are qualitative and quantitative differences in any given food due to factors such as cultivar/variety, maturity at harvest, climate/geographic site of production, season, part of the plant utilized, conditions during agricultural production, postharvest handling, processing and storage conditions [23].

\section{Conclusion}

The HPLC method validated in this study successfully determined lutein and $\beta$-carotene in Asian leafy vegetables, and lycopene in freeze-dried tomato. The data obtained in this study can be used to estimate the $\beta$-carotene contribution to dietary carotenoids intake, expressed in $\mathrm{RE}$. The lowest $\beta$-carotene, $1974 \mu \mathrm{g} / 100 \mathrm{~g}$, was measured in Chinese mustard, and consuming $100 \mathrm{~g}$ of this vegetable would contribute to $329 \mu \mathrm{g}$ RE (Table 1). It can therefore be suggested that Asian leafy vegetables measure here had substantial pro-vitamin A activity owing to their $\beta$-carotene contents.

\section{Conflict of Interest}

This study was conducted without any formal funding.

\section{Acknowledgments}

JA conceived the experiments, MVCH and HHR conducted the experiments and analyzed the results. All authors participated in the writing up and approved the manuscript for publication.

\section{References}

1. Amorim-Carrilho KT, Cepeda A, Fente C, Regal P. 2014. Review of methods for analysis of carotenoids. Trends Anal Chem 56: 49-73. https://doi.org/10.1016/j.trac.2013.12.011

2. Wills RBH, Wong AWK, Scriven FM, Greenfield H. 1984. Nutrient composition of Chinese vegetables. J Agr Food Chem 32(2): 413-416. https://doi.org/10.1021/jf00122a059

3. NHMRC. 2006. Vitamin A. NHMRC publications: Canberra, Australia.

4. Combs Jr GF. 2012. Vitamin A. In: Combs GF (ed) Vitamins $4^{\text {th }}$ edition. Academic Press: San Diego, USA, pp 93-138. http://doi. org/10.1016/B978-0-12-381980-2.00005-0

5. Ekman J. 2010. Asian Vegetables in Australia. In: International Horticulture Conference. Brisbane.

6. García-Plazaola JI, Becerril JMN. 1999. A rapid high-performance liquid chromatography method to measure lipophilic antioxidants in stressed plants: simultaneous determination of carotenoids and tocopherols. Phytochemical Analysis 10(6): 307-313. https:// doi.org/10.1002/(SICI)1099-1565(199911/12)10:6<307::AIDPCA477>3.0.CO;2-L

7. Taungbodhitham AK, Jonesb GP, Wahlqvistc ML, Briggsb DR. 1998. Evaluation of extraction method for the analysis of carotenoids in fruits and vegetables. Food Chem 63(4): 577-584. https://doi.org/10.1016/ S0308-8146(98)00011-9

8. Khachik F, Goli MB, Beecher GR, Holden J, Lusby WR, et al. 1992. Effect of food preparation on qualitative and quantitative distribution of major carotenoid constituents of tomatoes and several green vegetables. J Agr Food Chem 40(3): 390-398. https://doi.org/10.1021/jf00015a006

9. Bernhardt S, Schlich E. 2006. Impact of different cooking methods on food quality: retention of lipophilic vitamins in fresh and frozen vegetables. J Food Engg 77(2): 327-333. https://doi.org/10.1016/j. jfoodeng.2005.06.040

10. Miglio C, Chiavaro E, Visconti A, Fogliano V, Pellegrini N. 2008. Effects of different cooking methods on nutritional and physicochemical characteristics of selected vegetables. J Agric Food Chem 56(1): 139-147. https://doi.org/10.1021/jf072304b

11. Kao FJ, Chiu YS, Tsou MJ, Chiang WD. 2012. Effects of Chinese domestic cooking methods on the carotenoid composition of vegetables in Taiwan. LWT-Food Science and Technology 46(2): 485-492. https:// doi.org/10.1016/j.lwt.2011.11.019

12. Aman R, Schieber A, Carle R. 2005. Effects of heating and illumination on Trans-Cis isomerization and degradation of $\beta$-carotene and lutein in isolated spinach chloroplasts. J Agric Food Chem 53(24): 9512-9518. https://doi.org/10.1021/jf050926w

13. Wills RBH, Rangga A. 1996. Determination of carotenoids in Chinese vegetables. Food Chem 56(4): 451-455. https://doi.org/10.1016/03088146(95)00226-X 
14. Rodriguez-Amaya DB. 2000. Some considerations in generating carotenoid data for food composition tables. J Food Compost Anal 13(4): 641-647. https://doi.org/10.1006/jfca.2000.0915

15. Wills RBH, Nurdin H, Wootton M. 1988. Separation of carotenes and xanthophylls in fruit and vegetables by HPLC. Journal of Micronutrient Analysis 4(2): 87-98.

16. Hanson P, Ray-Yu Y, Lien-chunget C, Ledesma, L Ledesma D. 2011. Carotenoids, ascorbic acid, minerals, and total glucosinolates in choysum (Brassica rapa cvg. parachinensis) and kailaan (B. oleraceae Alboglabra group) as affected by variety and wet and dry season production.J Food Comp Anal 24(7): 950-962. https://doi.org/10.1016/j.jfca.2011.02.001

17. Hanson P, Ray-Yu Y, Lien-chunget C, Ledesma, L Ledesma D. 2009. Contents of carotenoids, ascorbic acid, minerals and total glucosinolates in leafy brassica pakchoi (Brassica rapa L. chinensis) as affected by season and variety.J Sci Food Agric 89(5): 906-914. https://doi.org/10.1002/jsfa.3533

18. USDA. 2015. USDA Nutrient Data Laboratory.

19. Pasaporte MS, Rabaya FJR, Toleco MM, Flores DM. 2014.
Xanthophyll content of selected vegetables commonly consumed in the Philippines and the effect of boiling. Food Chem 158: 35-40. https://doi. org/10.1016/j.foodchem.2014.02.090

20. Greenfield H, Southgate DAT. 2003. Food composition data: production, management and use. In: Burlingame BA, Charrondiere UR (eds) Food and Agriculture Organization of the United Nations, Rome, Italy

21. Ollilainen V, Linkola EK, Varo PT, Koivistoinen PE. 1989. Carotenoids in finnish foods: vegetables, fruits, and berries. J Agric Food Chem 37(3): 655-659. https://doi.org/10.1021/jf00087a017

22. Dias MG, Camões MF, Oliveira L. 2008. Uncertainty estimation and in-house method validation of HPLC analysis of carotenoids for food composition data production. Food Chem 109(4): 815-824. https://doi. org/10.1016/j.foodchem.2007.12.026

23. Rodriguez-Amaya DB, Kimura M, Godoy HT, Amaya-Farfan J. 2008. Updated Brazilian database on food carotenoids: factors affecting carotenoid composition. J Food Comp Anal 21(6): 445-463. https://doi. org/10.1016/j.jfca.2008.04.001 